[Agr. Biol. Chem., Vol. 34, No. 8, p. 1198 1203, 1970]

\title{
Diterpenoid Total Synthesis
}

\section{Part XII. ${ }^{\dagger}$ Racemic 4-Epipimaric and 4-Episandaracopimaric Acids}

\author{
By Kenji Mori and Masanao Matsui
}

Department of Agricultural Chemistry, Faculty of Agriculture,

The University of Tokyo, Bunkyo-ku, Tokyo, 113

Received January 24, 1970

A total synthesis of racemic 4-epipimaric and 4-episandaracopimaric acids is described.

(-)-4-Epipimaric acid [(-)-pimara-8(14), 15- the parent hydrocarbon, (-)-pimara-8(14), 15dien-19-oic acid, Ia] is a diterpene recently diene, acts as a precursor of gibberellic acid isolated from the roots of Aralia cordata Thunb. When fed to Gibberella fujikuroi., ${ }^{3, f, 4,5)}$

(Japanese name: Udo) by Shibata and his co- As a part of our efforts to synthesize diterworkers. ${ }^{1,2)}$ Hanson and White also isolated penes with an axial carboxyl group at C-4 the acid from spikenard root and showed that such as the gibberellins ${ }^{61}$ and kaur-16-en-19-

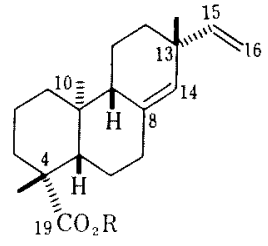

Ia $\quad \mathrm{R}=\mathrm{H}$

Ib $\mathrm{R}=\mathrm{Me}$

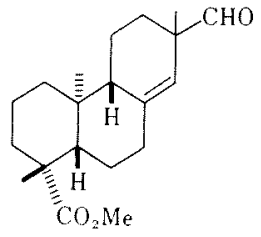

$\mathrm{V}$

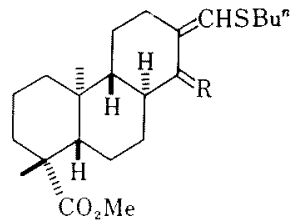

II $\mathrm{R}=\mathrm{O}$

III $\mathrm{R}=\stackrel{\mathrm{H}}{\mathrm{OH}}$

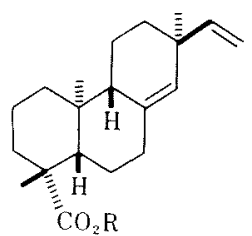

VIa $\mathrm{R}=\mathrm{H}$

VIb $\mathrm{R}=\mathrm{Me}$<smiles>CC(=O)[C@H]1CCC[C@]2(C)[C@@H]3CCC(C=O)=C[C@H]3CC[C@H]12</smiles>

IV<smiles>C=C[C@]1(C)C=C2CC[C@H]3[C@@](C)(CO)CCC[C@]3(C)[C@H]2CC1</smiles>

VIII $\dagger$ Part XI, K. Mori and M. Matsui, Tetrahedron, 24, 6573 (1968).

1) S. Shibata, S. Mihashi and O. Tanaka, Tetrahedron Letters, 1967, 5241 .

2) S. Mihashi, I. Yanagisawa, O. Tanaka and S. Shibata, ibid., 1969, 1683.
3) J. R. Hanson and A. F. White, Chem. Commun, 1968, 1689; Idem., J. Chem. Soc. (C), 1969, 981.

4) B. E. Cross and J. C. Stewart, Tetrahedron Letters, 1968, 5195.

5) B. E. Cross and J. C. Stewart, ibid., 1968, 6321.

6) K. Mori, M. Shiozaki, N. Itaya, M. Matsui and Y. Sumiki, Tetrahedron, 25, 1293 (1969). 
oic acid, ${ }^{71}$ we planned an approach to the racemic acid (Ia) ${ }^{*}$ starting from the previously described keto ester (II). ${ }^{7}$ Our synthetic route essentially parallels that employed for the synthesis of ( \pm )-pimara-8(14), 15-diene by Ireland and Schiess. ${ }^{81}$

The keto ester (II) was reduced with sodium borohydride to give an oily hydroxy ester (III). This was treated with mercuric chloride in ethanol to give crystalline aldo ester (IV) in $69 \%$ yield from II. ${ }^{c f \cdot 9,10}$ Methylation of the unsaturated aldehyde (IV) was achieved by treatment with a great excess of methyl iodide and potassium $t$-butoxide to give a mixture of $3, \gamma$-unsaturated aldehydes (V) epimeric at C-13. The mixture smoothly reacted with triphenylmethylene phosphorane in $\mathrm{DMSO}^{12}$ to give a mixture of methyl ( \pm )-4-epipimarate (Ib) and methyl ( \pm )-4-episandaracopimarate (VIb). This was chromatographed on alumina impregnated with silver nitrate $^{12 /}$ to effect separation of the $\mathrm{C}-13$ epimers. The desired crystalline ester (Ib) with an axial vinyl group at $\mathrm{C}-13$ was eluted first and then the oily epimer (VIb) with an equatorial vinyl group followed. The NMR spectra at $100 \mathrm{MHz}$ of the two esters exhibited significant difference with each other, although the IR spectra as films were very similar. Thus the vinylic protons $\left(15-\mathrm{H}\right.$ and $\left.16-\mathrm{H}_{2}\right)$ of the ester $\mathrm{Ib}$ absorbed at $\delta 5.60 \sim 5.88$ (sextet) and at $4.80 \sim 5.00$ (quintet) ppm representing

* Although the formulas depicted represent only one enantiomer, they are taken to mean a racemate in the cases of synthetic materials.

7) K. Mori and M. Matsui, Tetrahedron, 24, 3095 (1968).

8) R. E. Ireland and P. W. Schiess, J. Org. Chem., 28, 6 (1963).

9) R. F. Church and R. E. Ireland, ibid., 28, 17 (1963).

10) K. Mori and M. Matsui, Tetrahedron Letters, 1969, 4435 .

11) R. Greenwald, M. Chaykovsky and E. J. Corey, J. Org. Chem., 28, 1128 (1963).

12) a) D. F. Zinkel and J. W. Rowe, J. Chromatog., 13, $74(1964)$. b) A. W. Burgstahler and J. N. Marx, J. Org. Chem., 34, 1550 (1969). an $\mathrm{ABC}$ type splitting ${ }^{13.14)}$ very similar to that of methyl pimarate ( $\mathrm{Ib}$, antipodal framework with an $\alpha$-equatorial $\mathrm{CO}_{2} \mathrm{Me}$ at $\mathrm{C}$-4). On the other hand the corresponding absorptions of the ester VIb appeared at $05.68 \sim 5.96$ (quartet), at $4.95 \sim 5.00$ (quartet) and at $4.80 \sim$ 4.84 (triplet) representing an $\mathrm{ABX}$ type splitting similar to that of methyl sandaracopimarate (VIb, antipodal framework with an $\alpha$-equatorial $\mathrm{CO}_{2} \mathrm{Me}$ at $\mathrm{C}$-4). ${ }^{131}$

The corresponding racemic crystalline acids, 4-epipimaric (Ia) and 4-episandaracopimaric (VIa) acids, were prepared from the esters (Ib and VIb) by treatment with potassium $t$-butoxide in DMSO. ${ }^{15)}$

The IR (in carbon tetrachloride) and NMR (in deuteriochloroform) spectra of the racemic acid (Ia) and the ester (Ib) were identical with those of the natural acid (Ia) and the ester (Ib) in every detail. The ester was also identified by GLC comparison. The NMR spectra of the natural and racemic acids (Ia) and that of the racemic acid (VIa) are shown in Figs. $1 \sim 3$. The splitting patterns observed in the olefinic regions (see the enlarged spectra) are same as those observed in the cases of the corresponding esters ( $\mathrm{Ib}$ and $\mathrm{VIb}$ ). The acid Ia exhibited an ABC type splitting, while VIa showed an ABX type.

Although no occurrence of 4-episandaracopimaric acid (VIa) is reported hitherto, it is highly probable to be found in nature in view of the increasing examples of sets of diterpene acids with an axial or an equatorial carboxyl group at C-4 such as kaur-16-en-19oic $^{161}$ and kaur-16-en-18-oic ${ }^{171}$ acids, dehydro-

13) E. Wenkert and P. Beak, J.Am. Chem. Soc., 83,998 (1961).

14) R. M. Carman, Austral. J. Chem., 16, 1104 (1963).

15) F. C. Chang and N. F. Wood, Tetrahedron Letters, 1964, 2969.

16) C. A. Henrick and P. R. Jefferies, Austral. J. Chem., 17, 915 (1964).

17) G. Hugel, L. Lods, J. M. Mellor, D. M. Theobald and G. Ourisson, Bull. soc. chim. France, 1965, 2882. 


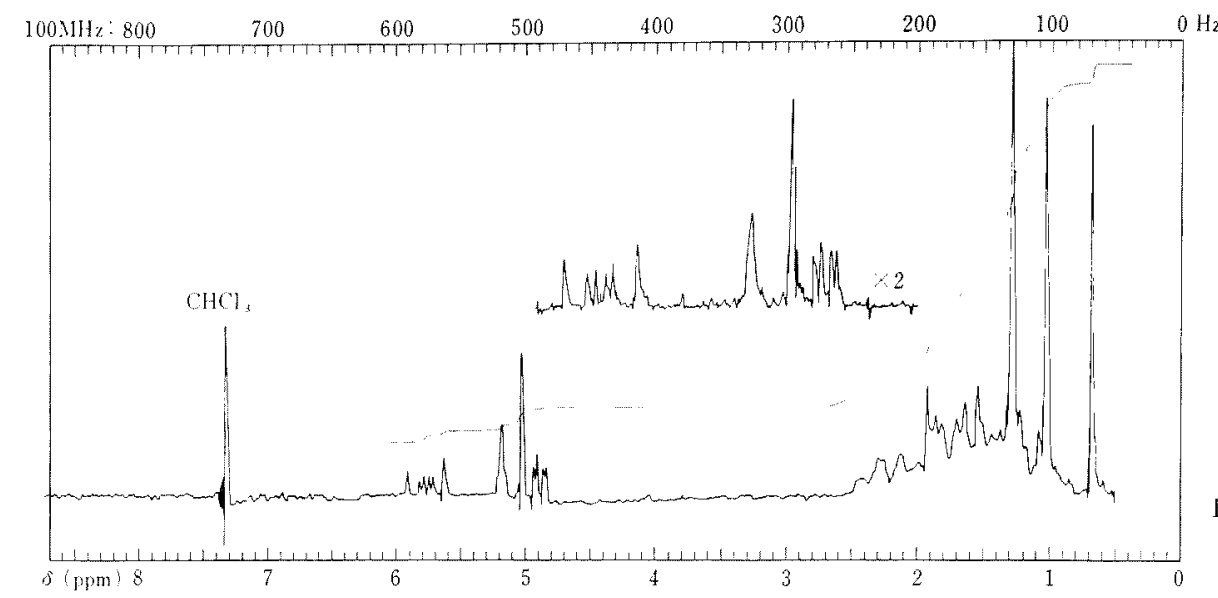

FIG. 1.

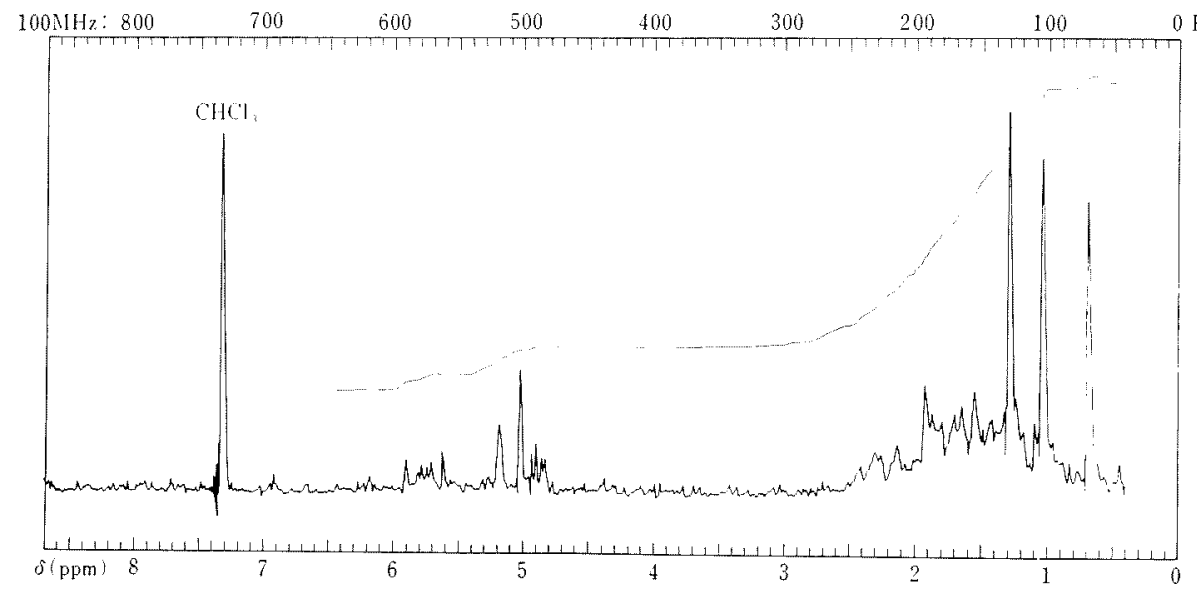

FIG. 2.

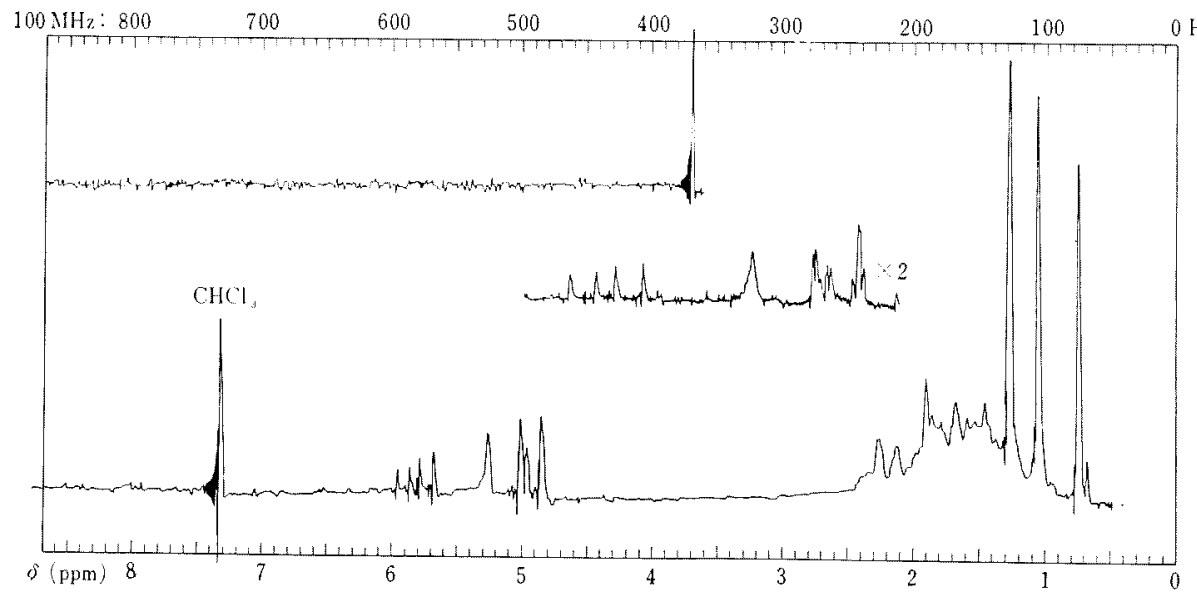

FIG. 3.

NMR Spectra of the Acids.

FIG, 1. (-)-4-Epipimaric Acid (Ia).

FIG. 3. (5.)-4-Episandaracopimaric Acid (VIa).

Measured in $\mathrm{CDCl}_{3}$ by a $\mathrm{JNM}-4 \mathrm{H}-100$ spectrometer at $100 \mathrm{MHz}$. The chemical shift, $\partial$-scale, is based on TMS as an internal standard. The enlarged spectra of the olefinic 
abietic $^{181}$ and 4-epidehydroabietic acids ${ }^{19-211}$ and the present case, pimaric ${ }^{22}$ and 4-epipimaric acids. ${ }^{*}$

\section{EXPERIMENTAL}

All mps were uncorrected. IR spectra refer to Nujol mulls for solid samples and films for oils. NMR spectra were recorded at $100 \mathrm{MHz}$ in $\mathrm{CDCl}_{3}$ with TMS as an internal standard.

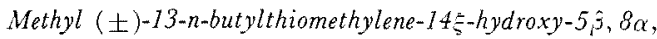

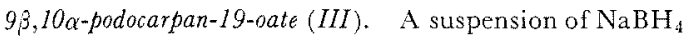
$(1.0 \mathrm{~g})$ in $950 \% \mathrm{EtOH}(50 \mathrm{ml})$ was added portionwise to a stirred and ice-cooled solution of II $(4.1 \mathrm{~g})$ in THF $(30 \mathrm{ml})$. After the addition, the mixture was stirred for $2 \mathrm{hr}$ at $5 \sim 10^{\circ} \mathrm{C}$, concentrated in vacuo, diluted with water and extracted with ether. The ethereal extract was washed with sat $\mathrm{NaCl}$ aq, dried $\left(\mathrm{MgSO}_{4}\right)$ and concentrated to give an oil. This was employed for the next step without characterization.

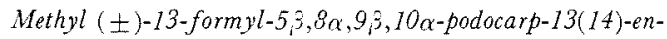
19-oate (IV). A solution of III (from $4.1 \mathrm{~g}$ of II) in $95 \% \mathrm{EtOH}(60 \mathrm{ml})$ was mixed with u suspension of $\mathrm{CdCO}_{3}(2.0 \mathrm{~g})$ in a solution of $\mathrm{HgCl}_{2}(2.9 \mathrm{~g})$ in $95^{\circ} \mathrm{o}$

18) C. Tabacik-Wlotzka, Bull. soc. chim. France, 1964,618 .

19) R. M. Carman and H. C. Deeth, Austral. J. Chem., 20, 2789 (1967).

20) L. J. Gough, Tetrahedron Letters, 1968, 295.

21) R. M. Carman, H. C. Deeth, R. A. Marty, K. Mori and M. Matsui, ibid., 1968, 3359.

22) J. L. Simonsen and D. H. R. Barton, "The Terpenes," Vol. III, Cambridge University Press, 1951, pp. $447 \sim 56$.

* Very recently the isolation of sandaracopimara8(14), 15-dien-19-ol (VII) from Dacrydium colensoi has been reported.231 A racemic alcohol (VII), sharply melting at $103 \sim 104^{\circ} \mathrm{C}$, was obtained by the reduction of VIb with lithium aluminum hydride. Its NMR spectrum was quite similar to that of the natural alcohol, especially in quaternary methyl, hydroxym methylene and olefnic regions but not identical with that of the natural material, especially in methylene region $(\delta) 1.20 \sim 2.50)$. The GLC retention time of our synthetic alcohol (VII) differed from that of the natural alcohol with the assigned structure VII. Since the natural material was available in a very minute amount, no detailed comparisons were possible and no definite conclution could be stated at present.

23) P.K. Grant, C. Huntrakul and J.M. Robertson, Austral. J. Chem., 22, 1265 (1969).
EtOH $(20 \mathrm{ml})$. The mixture was stirred and heated under reflux for $5 \mathrm{~min}$, concentrated in vacuo, diluted with benzene and water and filtered. The benzene layer was separated and the aqueous layer was extracted with benzene. The combined benzene solution was washed with water and sat $\mathrm{NaCl} a q$, dried $\left(\mathrm{MgSO}_{4}\right)$ and concentrated in vacuo to give $2.2 \mathrm{~g}(690 \mathrm{~g}$ from II) of crystalline IV. Recrystallization from EtOAc-pet, ether gave prisms, $\mathrm{mp} 127 \sim 128^{\circ} \mathrm{C}$; vms $2720,1700,1662,1630,1250,1210,1190 \mathrm{~cm}^{-1} ; 00.68$ $(3 \mathrm{H}, \mathrm{s}), 1.20(3 \mathrm{H}, \mathrm{s}), 3.64(3 \mathrm{H}, \mathrm{s}), 6.54(1 \mathrm{H}$, broad, $\mathrm{s})$, 9.43 (1H, s) ppm. Anal. Found: C, 74.92; H, 9.28. Calcd. for $\mathrm{C}_{19} \mathrm{H}_{28} \mathrm{O}_{3}: \mathrm{C}, 74.96 ; \mathrm{H}, 9.27 \%$.

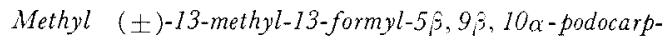
$8(14)$-en-19-oate $(V)$. A solution of IV $(2.1 \mathrm{~g})$ in dry 1,2-dimethoxyethane $(30 \mathrm{ml})$ was added to a solution of $t$-BuOK (from $12 \mathrm{~g}$ of $\mathrm{K}$ ) in $t$ - $\mathrm{BuOH}(250 \mathrm{ml}$ ) under $\mathrm{N}_{2}$. The solution was stirred and heated under reflux for $30 \mathrm{~min}$. Subsequently $\mathrm{Nel}(40 \mathrm{ml})$ was added in one portion to the ice-cooled solution with stirring. The stirring was continued for $8 \mathrm{hr}$ under $\mathrm{N}_{2}$ at room temperature. The mixture was diluted with water to dissolve KI, concentrated in vacto and extracted with ether. The ethereal extract was washed with water and sat $\mathrm{NaCl}$ aq, dried $\left(\mathrm{MgSO}_{4}\right)$ and concentrated in vacuo to give an oily epimeric mixture at $\mathrm{C}-13$ of $\mathrm{V}(2.1 \mathrm{~g}), \nu_{\max } 2720,1715,1235,1170 \mathrm{~cm}^{-1}$. The NMR spectrum clearly indicates that this is a mixture of two epimers: $\alpha$-(ax)-formyl isomer, $\delta 0.50$ (C-4 Me), 1.05 (C-13 Me), 1.18 (C-10 Me), 3.56 $\left(\mathrm{CO}_{2} \mathrm{Me}\right), 5.18(\mathrm{C}-14 \mathrm{H}), 9.37$ (CHO); $\hat{j}$-(eq)-formyl isomer, $00.60(\mathrm{G}-4 \mathrm{Me}), 1.03(\mathrm{C}-13 \mathrm{Me}), 3.56\left(\mathrm{CO}_{2} \mathrm{Me}\right)$, $5.26(\mathrm{C}-1+\mathrm{H}), 9.27$ ( $\mathrm{CHO}) \mathrm{ppm}$.

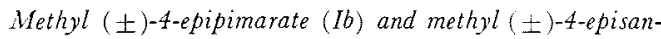
daracopimarate $(V I b)$. Triphenyl-methylphosphonium bromide $(7.8 \mathrm{~g})$ was added to a solution of sodium methylsulfinyl methylide (from $1.0 \mathrm{~g}$ of $50^{\circ} \mathrm{ONaH}$ ) in DMSO $(20 \mathrm{ml})$ under $\mathrm{N}_{2}$ with ice-cooling. The mixture was stirred for $10 \mathrm{~min}$ to yield an orangered solution of the Wittig reagent. A solution of $\mathrm{V}$ $(2.1 \mathrm{~g})$ in DMSO $(20 \mathrm{ml})$ was added dropwise to the reagent and the mixture was stirred for $3 \mathrm{hr}$ at room temperature. Subsequently it was poured into icewater and extracted with $n$-hexane. The $n$-hexane layer was washed with water and sat $\mathrm{NaCl}$ aq, dried $\left(\mathrm{MgSO}_{4}\right)$ and concentrated in vacuo to give $2.5 \mathrm{~g}$ of oil including $0.5 \mathrm{~g}$ of mineral oil. This was chromatographed over $\mathrm{Al}_{2} \mathrm{O}_{3}-\mathrm{AgNO}_{3}$. A column $(40 \times$ $3.6 \mathrm{~cm}$ ) was prepared by mixing $\mathrm{Al}_{2} \mathrm{O}_{3}$ (300 mesh, 
$300 \mathrm{~g})$ and $\mathrm{AgNO}_{3} \mathrm{aq}(60 \mathrm{~g}$ in $80 \mathrm{ml})$ and drying it in an oven at $130^{\circ} \mathrm{C}$ for $1 \mathrm{hr}$. All fractions were $300 \mathrm{ml}$. The eluants were as follows: fractions No. $1 \sim 3$, pet. ether; No. $4 \sim 6$, pet. ether-ether $(9: 1)$; No. $7 \sim 21$, pet. ether-ether $(85: 15)$. Fractions No. $1 \sim 11$ gave hydrocarbons. Fractions No. 12 and 13 gave an unidentified oil with a carbonyl absorption in IR spectrum (185 mg). Fraction No. 14 gave almost pure methyl (土)-4-epipimarate (Ib, $95 \mathrm{mg}$ ). Fractions No. $15 \sim 20$ gave a mixture of $\mathrm{Ib}$ and VIb (1.112 g).

The ester Ib gradually crystallized. Recrystallization from pet. ether gave rhombs, mp $68 \sim 69^{\circ} \mathrm{C}$; עmax $1715,1630(w), 1345(w), 1325(w), 1240,1225,1200$, $1150,1000,920,865,850 \mathrm{~cm}^{-1} ; \nu_{\max }\left(\mathrm{CCl}_{4}\right), 2945$, $1735(\mathrm{~s}), 1635(\mathrm{w}), 1445(\mathrm{~m}), 1210(\mathrm{~m}), 1180(\mathrm{~m})$, 1165 (m), 1145 (s), 1135 (sh.), 1118 (sh), 1085 (w), $1022(\mathrm{w}), \sim 975(\mathrm{w}), 915(\mathrm{~m}), 855(\mathrm{w}), 845(\mathrm{w}) \mathrm{cm}^{-1}$; o $0.55(3 \mathrm{H}, \mathrm{s}), 1.00(3 \mathrm{H}, \mathrm{s}), 1.20(3 \mathrm{H}, \mathrm{s}), 3.62(3 \mathrm{H}$, s), $4.80 \sim 5.00(2 \mathrm{H}$, quintet $), 5.10(1 \mathrm{H}$, broad $\mathrm{s})$, $5.60 \sim 5.88$ ( $1 \mathrm{H}$, sextet) ppm; GLC: Column, $3 \%$ SE30 on Celite $545,2 \mathrm{~m} \times 3 \mathrm{~mm}$ i.d. at $210^{\circ} \mathrm{C}$, Carrier gas, $\mathrm{N}_{2}, 0.8 \mathrm{~kg} / \mathrm{cm}^{2}, \mathrm{R}_{t} 11.0 \mathrm{~min}$. The IR $\left(\mathrm{CCl}_{4}\right)$, NMR and GLC data are indistinguishable from those of the natural product kindly provided by Dr. Mihashi of Tokyo College of Pharmacy. Anal. Found: C, 80.00; H, 10.32. Calcd. for $\mathrm{C}_{21} \mathrm{H}_{32} \mathrm{O}_{2}: \mathrm{C}, 79.70 ; \mathrm{H}$, $10.19 \%$.

A pure sample of the ester VIb was obtained by treating the pure VIa (see below) with $\mathrm{CH}_{2} \mathrm{~N}_{2}$ but it could not be crystallized. $\nu_{\max } 1715,1630$ (w), 1345 (w), 1325(w), 1240, 1225, 1200, 1150, 1000, 920,850 $\mathrm{cm}^{-1}$. This spectrum is very similar to that of the almost pure Ib measured as a film except that an absorption at $865 \mathrm{~cm}^{-1}$ is very weak in the spectrum of VIb. $\delta 0.65(3 \mathrm{H}, \mathrm{s}), 1.06(3 \mathrm{H}, \mathrm{s}), 1.22(3 \mathrm{H}, \mathrm{s}), 3.64(3 \mathrm{H}, \mathrm{s})$, $4.80 \sim 5.00(2 \mathrm{H}$, septet), 5.26 ( $1 \mathrm{H}$, broad $\mathrm{s}), 5.68 \sim 5.96$ $(1 \mathrm{H}, \mathrm{q})$ [or $4.90\left(1 \mathrm{H}, \mathrm{q}, \mathrm{H}_{\mathrm{A}}\right), 4.92\left(1 \mathrm{H}, \mathrm{q}, \mathrm{H}_{\mathrm{B}}\right), 5.82$ $\left.\left(1 \mathrm{H}, \mathrm{q}, \mathrm{H}_{\mathrm{X}}\right), J_{\mathrm{AB}}=2, J_{\mathrm{AX}}=17, J_{\mathrm{BX}}=10 \mathrm{~Hz}\right] \mathrm{ppm}$.

( \pm )-4-Epipimaric acid (Ia). Solid $t$-BuOK obtained by evaporation in vacuo of the solvent from a solution of $\mathrm{K}(0.2 \mathrm{~g})$ in $t-\mathrm{BuOH}(10 \mathrm{ml})$ was dissolved in dry DMSO $(5 \mathrm{ml})$ by gentle heating. This was added to a solution of crystalline $\mathrm{Ib}(40 \mathrm{mg})$ in DMSO $(1 \mathrm{ml})$. The mixture was stirred and heated at $100^{\circ} \mathrm{C}$ for $1.5 \mathrm{hr}$ under $\mathrm{N}_{2}$. After cooling it was diluted with water and the acid fraction was taken in ether in the usual manner. As the Na salt of $\mathrm{la}$ is soluble in ether, care should be taken during the separation not to discard the necessary material. The ethereal extract was washed with water and sat $\mathrm{NaCl}$ aq, dried $\left(\mathrm{MgSO}_{4}\right)$ and concentrated in vacuo. The residue was triturated with ether to give $23 \mathrm{mg}$ of crystalline Ib. Recrystallization from EtOAc-pet. ether afforded prisms, $\mathrm{mp} 180 \sim 182^{\circ} \mathrm{C}$ (dec., sinter at $173^{\circ} \mathrm{C}$ ); $\nu_{\max } \sim 3200$ $\sim 2600,1680,1630$ (w), 1270, 1000, 960, 920, 865 (w), $850 \mathrm{~cm}^{-1} ; \nu_{\max }\left(\mathrm{CCl}_{4}\right) \sim 3100,2950, \sim 2650,1695$ (s), $1635(\mathrm{w}), 1465(\mathrm{~s}), 1445(\mathrm{~s}), 1430(\mathrm{~m}), 1400(\mathrm{~m})$, $1355(w), 1325(w), 1310(w), 1255(\mathrm{~s}), 1180(\mathrm{~m}), 1175$ (m), $1145(\mathrm{w}), 1085(\mathrm{w}), 1023(\mathrm{~m}), 990(\mathrm{~m}), \sim 960(\mathrm{~m})$, $915(\mathrm{~s}), 860(\mathrm{w}), 845(\mathrm{~m}) \mathrm{cm}^{-1} ; \delta 0.69(3 \mathrm{H}, \mathrm{s}), 1.04$ $(3 \mathrm{H}, \mathrm{s}), 1.29(3 \mathrm{H}, \mathrm{s}), 4.82 \sim 5.02(2 \mathrm{H}$, quintet $), 5.18$ ( $1 \mathrm{H}$, broad, s), $5.62 \sim 5.90$ (1H, sextet) ppm. The IR and NMR spectra were in good accord with those of the natural product. Anal. Found: C, 79.12; H, 9.45. Calcd. for $\mathrm{C}_{20} \mathrm{H}_{30} \mathrm{O}_{2}: \mathrm{C}, 79.42 ; \mathrm{H}, 10.00 \%$.

(土)-4-Episandaracopimaric acid (VIa). Solid $t$-BuOK obtained by evaporation in vacuo of the solvent from a solution of $\mathrm{K}(2.0 \mathrm{~g})$ in $t-\mathrm{BuOH}(100 \mathrm{ml})$ was dissolved in dry DMSO $(50 \mathrm{ml})$ by gentle heating. A soluion of $\mathrm{Ib}$ and VIb $(1.1 \mathrm{~g}$, fractions No. $15 \sim 20$ of the chromatographic purification, predominantly VIb) in DMSO $(10 \mathrm{ml})$ was added to this solution. The mixture was stirred and heated at $100^{\circ} \mathrm{C}$ for $8 \mathrm{hr}$ under $\mathrm{N}_{2}$, poured into ice-water, acidified with $\mathrm{AcOH}$ and extracted with ether. The ethereal extract was washed with water and sat $\mathrm{NaCl}$ aq, dried $\left(\mathrm{MgSO}_{4}\right)$ and concentrated in vacuo. The residue was triturated with EtOAc-pet. ether to give $530 \mathrm{mg}$ of crude crystalline VIa contaminated with some Ia. Three recrystallizations from EtOAc-pet. ether gave pure VIa as prisms, $\mathrm{mp} 184 \sim 185^{\circ} \mathrm{C}$ (sinter at ca. $170^{\circ} \mathrm{C}$ ), $\nu_{\max }$ $\sim 3100-\sim 2600,1695,1635,1255,1183,992, \sim 930$, 906,857 (sh.), $850 \mathrm{~cm}^{-1}$; $\nu_{\text {max }}\left(\mathrm{CCl}_{4}\right) \sim 3100,2950$, $\sim 2650,1695(\mathrm{~s}), 1635(\mathrm{w}), 1460(\mathrm{~s}), 1440(\mathrm{~s}), 1430(\mathrm{~m})$, $1400(\mathrm{~m}), 1365(\mathrm{w}), 1355(\mathrm{w}), 1325(\mathrm{w}), 1310(\mathrm{w})$, 1255 (s), $1182(\mathrm{~m}), 1172(\mathrm{~s}), 1147$ (w), $1130(\mathrm{w}), 1085$ (w), $1023(\mathrm{~m}), 990(\mathrm{~m}), \sim 945(\mathrm{~m}), 910(\mathrm{~s}), 857$ (sh.), $840(\mathrm{~m}) \mathrm{cm}^{-1} ; \delta 0.75(3 \mathrm{H}, \mathrm{s}), 1.05(3 \mathrm{H}, \mathrm{s}), 1.28(3 \mathrm{H}$, s), $4.80 \sim 5.00(2 \mathrm{H}$, septet), $5.26(1 \mathrm{H}$, broad s), 5.68 $5.96(1 \mathrm{H}, \mathrm{q})$ [or $4.90\left(1 \mathrm{H}, \mathrm{q}, \mathrm{H}_{\mathrm{A}}\right), 4.98\left(1 \mathrm{H}, \mathrm{q}, \mathrm{H}_{\mathrm{B}}\right)$, $\left.5.82\left(1 \mathrm{H}, \mathrm{q}, \mathrm{H}_{\mathrm{X}}\right), J_{\mathrm{AB}}=2, J_{\mathrm{AX}}=17, J_{\mathrm{BX}}=10 \mathrm{~Hz}\right] \mathrm{ppm}$. Anal. Found: C, 79.08; H, 9.94. Calcd. for $\mathrm{C}_{20} \mathrm{H}_{30} \mathrm{O}_{2}$ : $\mathrm{C}, 79.42$; H, 10.00\%).

(士)-Sandaracopimaradien-19mol (VII). A solution of VIb $(218 \mathrm{mg})$ in THF $(20 \mathrm{ml})$ was added to a suspension of LAH ( $300 \mathrm{mg}$ ) in ether $(40 \mathrm{ml})$. The mixture was stirred and heated under reflux for $2 \mathrm{hr}$. After cooling the excess of LAH was destroyed by adding 
ice-water and the mixture was filtered through Celite. The Celite layer was washed with ether. The filtrate and washings were combined and the ethereal layer was separated. The ethereal solution was washed with sat $\mathrm{NaCl} \mathrm{aq}$, dried $\left(\mathrm{MgSO}_{4}\right)$ and concentrated in vacuo to give crude crystalline VII. Recrystallization from pet. ether gave $85 \mathrm{mg}$ (430) of pure VII as needles, $\mathrm{mp} 103 \sim 104^{\circ} \mathrm{C}, \nu_{\max } 3350,1665$ (w), $1630(w), 1040$, $1030,995,975,955,935,920,865(\mathrm{sh}), 855 \mathrm{~cm}^{-1}$; $\nu_{\max }$ $\left(\mathrm{CHCl}_{3}\right) \sim 3700, \sim 3100,1660,1630,1015,910,860,850$ $\mathrm{cm}^{-1} ; \delta 0.80(3 \mathrm{H}, \mathrm{s}), 1.04(3 \mathrm{H}, \mathrm{s}), 1.08(3 \mathrm{H}, \mathrm{s}), 3.42,3.84$ $\left(2 \mathrm{H}, \mathrm{AB}, J_{\mathrm{AB}}=11 \mathrm{~Hz}\right), 4.85 \sim 5.01$ ( $2 \mathrm{H}$, septet), 5.24 (1H, broad s), 5.68 5.96(1H, q) [or $4.90\left(1 \mathrm{H}, \mathrm{q}, \mathrm{H}_{\mathrm{A}}\right.$ ), $4.93\left(1 \mathrm{H}, \mathrm{q}, \mathrm{H}_{\mathrm{B}}\right), 5.82\left(1 \mathrm{H}, \mathrm{q}, \mathrm{H}_{\mathrm{X}}\right), J_{\mathrm{AB}}=1.5, J_{\mathrm{AX}}=17$, $\left.J_{\mathbf{B X}}=10 \mathrm{~Hz}\right] \mathrm{ppm}$. The NMR specrum was slightly different from that of the natural alcohol kindly provided by Professor P. K. Grant. Anal. Found: C,
83.19; H, 11.16. Calcd. for $\mathrm{C}_{20} \mathrm{H}_{32} \mathrm{O}: \mathrm{C}, 83.27 ; \mathrm{H}$, 11.18,\%. GLC: Column, 30, SE-30 on Celite 545, $2 \mathrm{~m} \times 3 \mathrm{~mm}$ i.d. at $210^{\circ} \mathrm{C}$, Carrier gas, $\mathrm{N}_{2}, 1.0 \mathrm{~kg} / \mathrm{cm}^{2}$, $\mathrm{R}_{t} 8.6 \mathrm{~min}$. cf. Prof. Grant's alcohol: $\mathrm{R}_{t} 8.0 \mathrm{~min}$.

Acknowledgements. We are indebted to Dr. S. Mihashi, Tokyo College of Pharmacy, for discussions. Samples of the natural acid (Ia) and its ester (Ib) were kindly given to us by Dr. S. Mihashi through the courtesy of Professors S. Shibata and O. Tanaka, Faculty of Pharmaceutical Sciences, this University, to whom we express our thanks. We gratefully appreciate the generosity of Professor P. K. Grant, University of Otago, for his gift of a small amount of his diterpene alcohol. Thanks are due to $\mathrm{Mr}$. K. Aizawa, this Department, for the NMR measurements. 